\title{
Implementing and evaluating the efficacy of an acute care urology model of care in a large community hospital
}

Abirami Kirubarajan; Roger Buckley; Shawn Khan; Rebecca Richard; Veselina Stefanova; Nicole Golda

University of Toronto, Toronto, ON, Canada

Cite as: Can Urol Assoc J 2020 March 23; Epub ahead of print. http://dx.doi.org/10.5489/cuaj.6371

Published online March 23, 2020

$* * *$

Abstract

Introduction: We implemented an acute care urology (ACU) model at a large Canadian community hospital to determine the impacts on safe and timely care of patients with renal colic. The model includes a dedicated ACU surgeon, a clinic for emergency department (ED) referrals, and additional daytime operating room blocks for urgent cases.

Methods: We conducted a chart review of 579 patients presenting to the ED with renal colic. Data was collected before (pre-intervention, September to November 2015) and after (postintervention, September to November 2016) implementation of the ACU model. Secondary methods of evaluation included surveying patients and $20 \mathrm{ED}$ physicians to capture subjective feedback.

Results: Of the 579 patients presenting with renal colic, 194 were diagnosed with an obstructing kidney stone and were referred to urology for outpatient care. The ED-to-clinic time was significantly lower for those in the ACU model $(\mathrm{p}<0.001)$. Furthermore, the ACU clinic resulted in significantly more patients being referred for outpatient care $(\mathrm{p}=0.0004)$. There was also higher likelihood that patients would successfully obtain an appointment post-referral $(\mathrm{p}=0.0242)$. The number of after-hours and weekend surgeries decreased significantly after dedicated ACU daytime operating room (OR) blocks were added in Sep $2015(\mathrm{p}<0.0001)$. All surveyed patients rated the care as either "excellent" or "very good," and all physicians believed the ACU model has improved patient care.

Conclusions: The ACU model has shown benefit in ensuring timely followup for ED patients, reducing use of after-hour OR time, and improving patient and physician satisfaction. 


\section{Introduction}

The Acute Care Surgery (ACS) model has gained popularity in general surgery and is quickly becoming the standard model for delivering emergency general surgery care across Canada. ${ }^{1}$ The ACS model involves the urgent assessment and treatment of surgical emergencies through rapid referral clinics and protected operating block times. Results from general surgery literature have shown this practice model to be effective in reducing emergency department (ED) wait times, time to consultation, and wait times for procedures. ${ }^{2-4}$ Furthermore, as the ACS model allows for predictable scheduling, the majority of general surgeons reported an improved balance when scheduling emergency versus elective procedures. ${ }^{5}$ This model of care has gained favour in general surgery, but has yet to be widely adopted in other surgical specialties. To our knowledge, there are no urology divisions in other Canadian hospitals that have implemented this model of care.

We implemented an Acute Care Urology ( $\mathrm{ACU}$ ) model in Toronto, Canada to address gaps in current emergency care in urology. At the community-based hospital where we conducted our study, many ED physicians had been concerned that urology patients were lost to follow-up, considering that average wait times ranged several months for an initial urology consultation. Furthermore, urology surgeons struggled to balance emergency referrals with previously scheduled elective surgery times. Urgent referrals would be seen by the on-call urologist, who would often have to perform urgent surgical cases after hours. Alternatively, elective cases would be cancelled or delayed to accommodate completion of more urgent cases. The standard model of practice could both compromise care for patients with emergency needs, promote patient dissatisfaction, as well as increase the risk of physician fatigue.

\section{Purpose and hypothesis}

The purpose of our study was to implement and evaluate an ACU model of care at a large community-based hospital. Our hypothesis was that the implementation of an ACU model would have positive outcomes on important patient flow metrics, namely ED length of stay, time from urology referral to consultation, and number of after-hours surgeries for patients presenting to the ED with "renal colic" and were confirmed to have an obstructing stone. We also hypothesized that ED physicians, urologists, and patients would be more satisfied with the quality of patient care.

\section{Methods}

\section{Details of the ACU model}

We implemented an ACU model in a stepwise approach. This included the enhanced use of dedicated ACU daytime operating room (OR) blocks every Tuesday and Thursday, which began in September 2014. We then included the addition of a dedicated ACU surgeon and creation of a rapid referral clinic for ED patient referrals in July 2016. 
In this revised model of urology care, the ACU surgeon saw all urgent urology outpatient referrals received from the ED (e.g. renal colic, hematuria, and urinary retention). The ACU surgeon was stationed at an outpatient care clinic, allowing them to see urgent referrals as well as perform minor procedures that could be accomplished under local anesthesia. Patients seen in referral who require operative care were prepared for the ACS-Urology OR block dedicated time in the operating room on Tuesday $(0730-1200)$ and Thursday $(0730-1530)$. Clinic time was available on weekdays (Monday $0800-1200$, Tuesday 1500 - 1600, Wednesday $1300-1600$, Thursday 1500 - 1600, Friday 0800 - 1200). A standard call arrangement remained for daytime (Monday to Friday) and evening and weekend call, in which a single on-call surgeon would complete urgent consultations and emergent operative cases as required. There are a total of six urologists practicing in our group.

\section{Research methods}

We conducted a manual chart review of 579 patients presenting to the ED with a complaint of "renal colic". Patients were considered to be eligible for analysis if they had a diagnosis of an "obstructing stone" (i.e. a stone within the ureter) and were referred to urology for outpatient assessment. Patients were excluded if they lacked satisfactory imaging, had a non-urologic diagnosis, were admitted to hospital care, or if they passed the stone while in the ED (Figure 1). Patient data was collected in two separate time periods to analyze impact on patient care before (“pre-intervention", September - November 2015) and after ("post-intervention”, September November 2016) implementation of the ACU model. Patient data was obtained from ICD codes from the Emergency Department and coded using anonymized numbers to maintain privacy.

Secondary methods of evaluation included a survey of ED physicians and urologists to capture subjective feedback of the ACU model through Likert scale data, adapted from a recent study by Wilgenbusch et al. ${ }^{6}$ Questions were asked via an online survey in order to gauge perception related to patient flow metrics and quality of care. All responses were anonymized. Patients also had the opportunity to provide feedback from July 2017 to September 2017, which was collected and analyzed using descriptive statistics. The combination of open-ended and closed-ended questions were developed after a literature search, adaptation from previous surveys, and consultation with stakeholders on the healthcare team.

\section{Statistical analysis}

Statistical analysis was prepared using "N $-1 " \chi^{2}$ test for comparison of proportions, as well as unpaired two-sided $t$-tests. A statistical significance of $p<0.05$ was considered significant. Survey data was analyzed through descriptive statistics.

\section{Results}




\section{Chart review}

Out of the 579 patients analyzed, 370 patients (169 pre-intervention and 201 post-intervention) were diagnosed with an obstructing kidney stone. 194 patients (72 pre-intervention and 122 postintervention) were referred for outpatient urological assessment following the diagnosis of an obstructing kidney stone. There was no significant difference in age or sex distribution in the pre- and post-intervention groups (Table 1).

The ED-to-clinic time was significantly lower for those in the ACU model $(\mathrm{p}<0.0001)$. The mean time to clinic was 15.76 days $(\mathrm{SD}=15.47$, range $=1-93)$ pre-intervention versus 4.17 days $(\mathrm{SD}=2.33$, range $=1-12)$ post-intervention. However, we did not observe a significant difference in ED wait-times before physician assessment, as shown in Table 2. The changes in time from assessment-to-procedure were also not statistically significant.

Furthermore, the ACU clinic resulted in significantly more patients successfully receiving outpatient care. Specifically, 51.1\% (72/141) of patients diagnosed with an obstructing stone were referred in the pre-intervention cohort in comparison to $70.5 \%(122 / 173)$ referred in the post-intervention cohort $(\mathrm{p}=0.0004)$. There was also a higher likelihood that patients would successfully obtain an appointment following referral $(p=0.0242)$. Fewer patients were lost to follow-up following the implementation of the ACU model. Prior to the establishment of the ACU clinic , 21/72 (29\%) or referred patients were never seen by a urologist, in comparison to $15 / 122(12.7 \%)$ after all referrals were streamlined to the ACU clinic $(p=0.006)$. Furthermore, these 15 patients were all contacted within 48 hours of receiving the referral and declined the appointment.

Balancing indicators were also considered, in order to determine whether an ACU model may hasten unnecessary investigations or surgeries. There was no difference in the proportion of patients who underwent a CT scan and/or ultrasound, with 90.69\% (263/290) pre-intervention and $93.77 \%(271 / 289)$ post-intervention undergoing imaging $(\mathrm{p}=0.1667)$. The number of patients assessed who proceeded to undergo surgical intervention (ureteroscopy, laser lithotripsy, +/- ureteric stent insertion) was similar with 15/51 (29.41\%) pre- intervention and 28/103 $(27.18 \%)$ post-intervention $(\mathrm{p}=0.77)$. Furthermore, based on pre-operative imaging, there was no statistically significant difference between the size of stone operated upon with the average size being $6.7 \mathrm{~cm}$ and $7.7 \mathrm{~cm}$ in the pre- and post- intervention groups, respectively. In the postintervention group, this average stone size of $7.7 \mathrm{~cm}$ compares to $4.3 \mathrm{~cm}$ in the group of patients who were managed conservatively and ultimately passed the obstructing stone spontaneously.

The number of after-hours and weekend surgeries decreased significantly after dedicated ACU daytime OR blocks were added in Sep 2014. Only 1/43 cases occurred after-hours (start time after 16:00) or on weekends of the combined pre- and post- intervention 6 month periods analyzed (September - November 2015 and 2016). However, in order to highlight the impact of adding the dedicated ACU daytime OR blocks on after- hours cases, comparable time periods were analyzed before and after Sept 2014. Retrospectively analyzing all stone procedures, 15.4\% 
$(19 / 123)$ of cases were performed after-hours or on weekends in Apr-Jun 2016, in contrast to 51\% (51/100) in Apr-Jun $2014(\mathrm{p}<0.0001)$.

\section{Feedback of providers and patients}

Results of the qualitative surveys were overwhelmingly positive. All 20 surveyed ED physicians were more confident that outpatients would be seen in a timely manner ( $85 \%$ strongly agree, $15 \%$ agree). Qualitative feedback included the belief that follow-up is more accessible and that ED physicians are less likely to page the on-call urologist, allowing them to discharge patients sooner. Overall satisfaction with the ACU model was 95\% satisfied, and all believe there has been a positive impact on patient care.

The urology group at the community hospital unanimously agreed that acute urology patient outcomes have improved since implementation of ACU and that since ACU implementation, patient consults are performed in a more timely fashion. $100 \%$ of urologists were "completely satisfied" with the addition of the ACU clinic, with qualitative feedback that the ACU clinic promotes collegiality among staff and improves the work environment.

Eleven patients provided voluntary feedback from July 2017 to September 2017, with $100 \%$ of the patients noting satisfaction with the clinic. $100 \%$ of the patients believed that waittime from ED to clinic was timely and that they were given very clear information about their care options.

\section{Discussion}

Ultimately, there were several key benefits of the ACU model in this study. The urologists at our hospital had unanimously agreed in our survey that after-hours surgeries contribute to burnout and dissatisfaction, which has been confirmed by previous literature as well. The significant decrease of after-hours surgeries has benefits for both provider satisfaction as well as increased patient safety. ${ }^{7}$ In addition, in the Ontario health system, after-hours surgeries are more costly for the hospitals due to payments of overtime for staffing as well as constraints on operating room space. The ACU model significantly decreased the number of after-hours surgeries, without incurring any delays in patients receiving their necessary procedures. Future research could investigate specific cost-benefit savings and the final dollar value saved for each acute care urologic case.

In addition, the ACU model resulted in more timely and reliable access of clinical care for patients. Providers could have greater trust that patients would be seen in a timely manner, while patients appreciated the additional support in their time of need. Loss of follow-up has been noted as a large issue for many patients, and the ACU model provides a potential solution to better organize care between the ED and specialists. There is a more direct and streamlined pathway for patients and providers following the diagnosis of their urgent urologic condition. In addition, it is important to note that the addition of an ACU surgeon and the ACU clinic did not 
lead to patients prematurely undergoing a surgical procedure as the stone size was not significantly different in patients who were operated on through the ACU model.

Another potential added benefit is the opportunity for increasing urologist employment in Canada through the creation of these specialized roles. The recent research by Hosier et al. suggests a relative paucity in Canadian urologist jobs, despite more than doubling the number of trainees per year. ${ }^{8}$ ACU programs at hospitals could create meaningful job opportunities for urologists that offer a mix of both medical and surgical experience, with hospitals incentivized to hire due to the cost-savings realized from reduced after-hours surgeries. At our hospital specifically, we were able to create a full-time job for a new urologist to join the group and focus on acute care as a career practice. However, further research is required to characterize how the ACU model may affect hiring trends, particularly regarding part-time employment and itinerant practice.

Contrary to our hypothesis, the ACU model did not result in significantly different wait times based on the time periods selected. However, ED wait times have risen nationally due to systemic factors according to the Canadian Institute for Health Information. As such, it is difficult to extrapolate the differences in hospital wait times due to other variables in the systems landscape. In addition, as the ACU model did not run weekend hours, there were often lags in assessment between Friday and Monday. Future models could expand to offering weekend clinics.

Another limitation of our analysis involves the restricted focus of renal colic when evaluating the ACU model. While the ACU clinic sees a wide array of urgent urologic concerns ranging from hematuria to urinary retention, renal colic was the most common presentation to the ACU clinic. Evaluating a single patient diagnosis allowed for better comparability of results and patient demographics. Moreover, we were unable to evaluate repeat visits to the ED or "bounce backs" from the ACU model, as there are many hospitals and EDs available in our catchment area. We were unable to access patient data from other hospitals to determine repeat admissions. Future research could involve collaboration between multiple hospitals in order to determine this information. In addition, patient feedback was very limited and may be skewed towards positive information, as only a select few patients decided to provide feedback following their experience at the ACU clinic. Finally, we were only able to complete questionnaires postintervention and not pre-intervention. Future research could more systematically survey patients in order to obtain more thorough results. 


\section{Conclusions}

The ACU model involves the creation of a rapid referral clinic dedicated to ED patient referrals, the addition of an ACU surgeon, and enhanced use of daytime OR blocks. The ACU model appears to be beneficial for both patients and providers through reducing ED-to-clinic time for renal colic, ensuring proper follow-up after diagnosis, and reducing the number of after-hours surgeries. 


\section{References}

1. Hameed SM, Brenneman FD, Ball CG, et al. General surgery 2.0: The emergence of acute care surgery in Canada. Can J Surg 2010;53:79-83.

2. Faryniuk AM, Hochman DJ. Effect of an acute care surgical service on the timeliness of care. Can J Surg 2013;56:187-91.

3. Ball CG, MacLean AR, Dixon E, et al. Acute care surgery: The impact of an acute care surgery service on assessment, flow, and disposition in the emergency department. Am J Surg 2012;203:578-83.

4. Qureshi A, Smith A, Wright F, et al. The impact of an acute care emergency surgical service on timely surgical decision-making and emergency department overcrowding. $J$ Am Coll Surg 2011;213:284-93.

5. Helewa RM, Kholdebarin R, Hochman DJ. Attending surgeon burnout and satisfaction with the establishment of a regional acute care surgical service. Can J Surg 2012;55:3126.

6. Wilgenbusch CS, Dust PW, Sunderland IR. Development of an acute care plastic surgery service in the saskatoon health region: effects on flexor tendon management. Plast Surg 2015;23:195-8.

7. Helewa RM, Kholdebarin R, Hochman DJ: Attending surgeon burnout and satisfaction with the establishment of a regional acute care surgical service. Can J surg. 2012, 55 (5): 312-316. 10.1503/cjs.000611.

8. Hosier GW, Touma NJ. Attitudes of graduating Canadian urology residents on the job market: Is it getting better or are we just spinning our wheels?. Can Urol Assoc $J$ 2018;12:104.

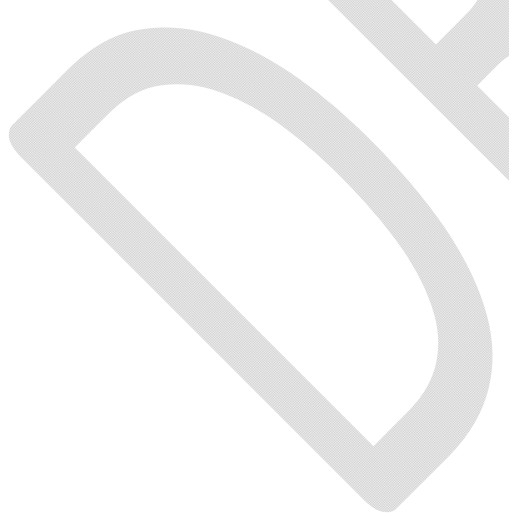




\section{Figures and Tables}

Fig. 1. Flowchart of patients assessed for eligibility pre-intervention. ED: emergency department.
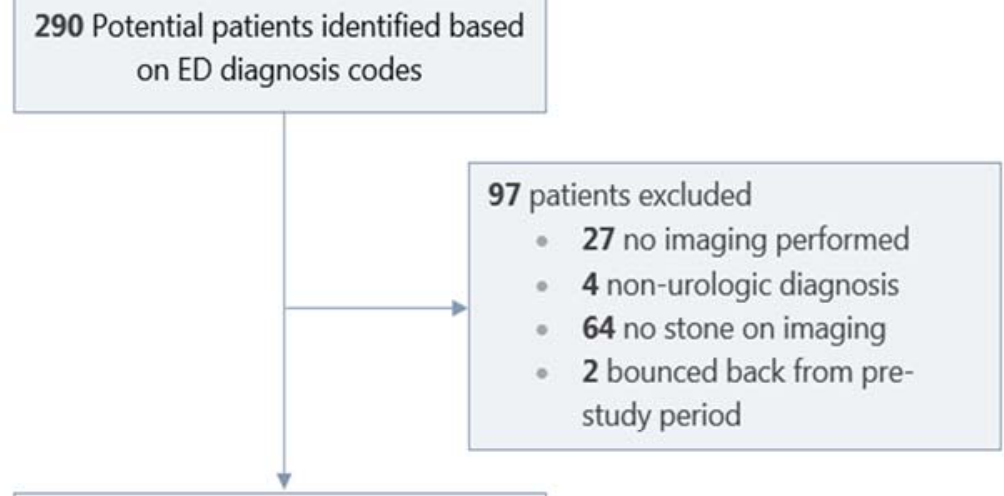

193 Patients with stone diagnosis assessed for eligibility

24 patients excluded

- 4 passed stone in ED

- 20 non-obstructing stone

169 Patients with obstructing stone diagnosis assessed for eligibility

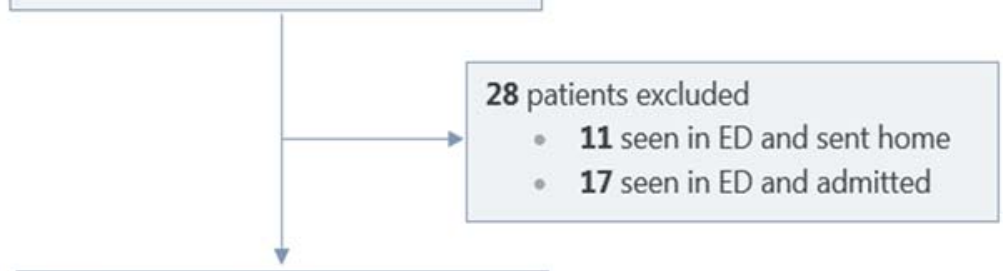

141 Patients with obstructing stone diagnosis remaining

69 patients excluded

- 69 with obstructing stone but not referred to Urology for outpatient assessment

72 Patients referred to urology for outpatient assessment 
Fig. 2. Flowchart of patients assessed for eligibility post-intervention. ED: emergency department.

289 Potential patients identified based on ED diagnosis codes

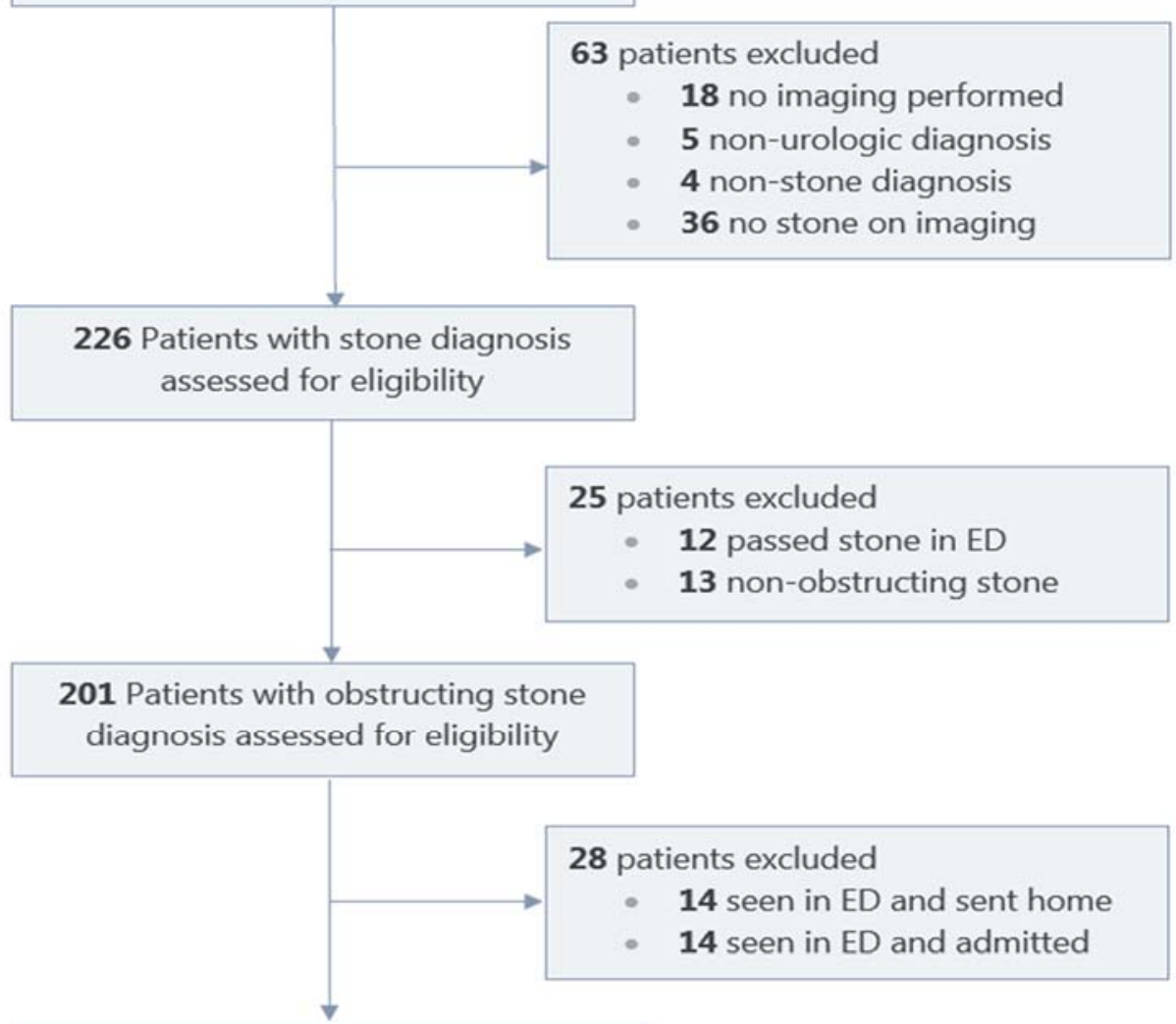

173 Patients with obstructing stone diagnosis remaining

51 patients excluded

- $\mathbf{5 1}$ with obstructing stone but not referred to Urology for outpatient assessment

122 Patients referred to urology for outpatient assessment 


\begin{tabular}{|l|c|c|c|}
\hline \multicolumn{1}{|l|}{ Table 1. Patient demographics } \\
\hline Variable & $\begin{array}{c}\text { Pre-intervention } \\
\mathbf{n}(\%)\end{array}$ & $\begin{array}{c}\text { Post-intervention } \\
\mathbf{n}(\%)\end{array}$ & $\mathbf{p}$ \\
\hline $\begin{array}{l}\text { Patients presenting to the } \\
\text { ED with a renal colic } \\
\text { complaint }\end{array}$ & 290 & 289 & \\
\hline $\begin{array}{l}\text { Sex distribution } \\
\text { Male }\end{array}$ & $187(64.5)$ & $186(64.4)$ & 0.98 \\
Female & $103(35.5)$ & $103(35.6)$ & 0.98 \\
\hline Age in years, mean (SD) & $48.61(14.55)$ & $48.87(15.14)$ & \\
Male & $48.94(14.25)$ & $49.55(14.74)$ & 0.83 \\
Female & $48.01(15.13)$ & $47.64(15.83)$ & 0.83 \\
\hline
\end{tabular}

ED: emergency department; SD: standard deviation.

\begin{tabular}{|c|c|c|c|}
\hline & $\begin{array}{c}\text { Pre- } \\
\text { intervention } \\
\text { n }(\%)\end{array}$ & $\begin{array}{c}\text { Post-intervention } \\
\text { n (\%) }\end{array}$ & $\mathbf{p}$ \\
\hline $\begin{array}{l}\text { Patients diagnosed with } \\
\text { obstructive kidney stone }\end{array}$ & 141 & 173 & \\
\hline $\begin{array}{l}\text { Proportion of diagnosed patients } \\
\text { referred to outpatient urology }\end{array}$ & $72 / 141(51.1 \%)$ & $122 / 173(70.5 \%)$ & $0.0004^{*}$ \\
\hline $\begin{array}{l}\text { Sex distribution of referrals } \\
\text { Male } \\
\text { Female }\end{array}$ & $\begin{array}{l}54(75 \%) \\
18(25 \%)\end{array}$ & $\begin{array}{l}77(63.11 \%) \\
45(36.89 \%)\end{array}$ & $\begin{array}{l}0.0884 \\
0.0884\end{array}$ \\
\hline Age in years, mean (SD) & $48(14)$ & $49(16.11)$ & 0.6619 \\
\hline $\begin{array}{l}\text { Proportion of patients assessed } \\
\text { by urologists as outpatient } \% \\
\text { patients seen }\end{array}$ & $51 / 72(70.83 \%)$ & $103 / 122(84.42 \%)$ & $0.0242^{*}$ \\
\hline $\begin{array}{l}\text { Proportion of referrals who } \\
\text { underwent a surgical procedure }\end{array}$ & $15 / 51(29.41 \%)$ & $28 / 103(27.18 \%)$ & 0.77 \\
\hline
\end{tabular}

*Statistical significance. SD: standard deviation. 


\begin{tabular}{|l|c|c|c|}
\hline \multicolumn{1}{|l|}{ Table 3. Comparison of number of imaging tests performed } \\
\hline & $\begin{array}{c}\text { Pre-intervention } \\
\text { n (\%) }\end{array}$ & $\begin{array}{c}\text { Post-intervention } \\
\text { n (\%) }\end{array}$ & p \\
\hline $\begin{array}{l}\text { Proportion of patients with } \\
\text { renal colic in the ED who } \\
\text { underwent imaging }\end{array}$ & $263 / 290(90.69 \%)$ & $271 / 289(93.77 \%)$ & 0.1667 \\
$\begin{array}{l}\text { Number of CTs } \\
\text { Number of USs }\end{array}$ & $178(66.17)$ & $190(67.37)$ & \\
& $91(33.83)$ & $92(32.62)$ & 0.76 \\
\end{tabular}

CT: computed tomography; ED: emergency department; US: ultrasound.

\section{Table 4. Wait times}

\begin{tabular}{|c|c|c|c|c|c|c|c|}
\hline \multirow[t]{2}{*}{ Wait time } & \multicolumn{3}{|c|}{ Pre-intervention group } & \multicolumn{3}{|c|}{ Post-intervention group } & \multirow[t]{2}{*}{$\mathbf{p}$} \\
\hline & $\begin{array}{c}\text { Patients, } \\
\text { n }\end{array}$ & $\begin{array}{c}\text { Mean } \\
\text { (SD) }\end{array}$ & $\begin{array}{c}\text { Median } \\
\text { (IQR) }\end{array}$ & $\begin{array}{c}\text { Patients, } \\
\text { n }\end{array}$ & $\begin{array}{c}\text { Mean } \\
\text { (SD) }\end{array}$ & $\begin{array}{c}\text { Median } \\
\text { (IQR) }\end{array}$ & \\
\hline $\begin{array}{l}\text { Patients } \\
\text { with renal } \\
\text { colic in the } \\
\text { ED } \\
\text { (minutes) }\end{array}$ & 290 & $\begin{array}{c}208.26 \\
(156.94)\end{array}$ & $\begin{array}{c}177 \\
(104.00- \\
264.25)\end{array}$ & $238^{*}$ & $\begin{array}{c}221.30 \\
(165.01)\end{array}$ & $\begin{array}{c}193.00 \\
(114.50- \\
288.50)\end{array}$ & 0.3537 \\
\hline
\end{tabular}

*Data not available for 51 patients. ED: emergency department. 
Table 5. Comparison of wait times spent by the referral group

\begin{tabular}{|c|c|c|c|c|c|c|c|}
\hline \multirow[t]{2}{*}{ Wait time } & \multicolumn{3}{|c|}{ Pre-intervention group } & \multicolumn{3}{|c|}{ Post-intervention group } & \multirow[t]{2}{*}{$\mathbf{p}$} \\
\hline & $\begin{array}{c}\text { Patients, } \\
\text { n }\end{array}$ & $\begin{array}{l}\text { Mean } \\
\text { (SD) }\end{array}$ & $\begin{array}{c}\text { Median } \\
\text { (IQR) }\end{array}$ & $\begin{array}{c}\text { Patients, } \\
\text { n }\end{array}$ & $\begin{array}{c}\text { Mean } \\
\text { (SD) }\end{array}$ & Median & \\
\hline $\begin{array}{l}\text { Time spent } \\
\text { in ED }\end{array}$ & 72 & $\begin{array}{c}3 \text { hrs } 39 \mathrm{~min} \\
(2 \mathrm{hrs} 17 \\
\min )\end{array}$ & $\begin{array}{c}3 \mathrm{hrs} 23 \\
\min \end{array}$ & & $\begin{array}{c}3 \mathrm{hr} 29 \mathrm{~min} \\
(2 \mathrm{hrs} 12 \\
\min )\end{array}$ & $\begin{array}{c}3 \mathrm{hrs} 13 \\
\min \end{array}$ & 0.6151 \\
\hline $\begin{array}{l}\text { From ED to } \\
\text { urological } \\
\text { assessment } \\
\text { (days) }\end{array}$ & 51 & $\begin{array}{c}15.76 \\
(15.47)\end{array}$ & $13(1-93)$ & 103 & 4.17 (2.33) & $\begin{array}{c}4.0 \\
(1-12)\end{array}$ & $<0.0001$ \\
\hline $\begin{array}{l}\text { From ED to } \\
\text { urologic } \\
\text { procedure }\end{array}$ & 15 & $24.1(34.1)$ & $11(4-141)$ & 28 & $14.1(15.1)$ & $9(2-69)$ & 0.1889 \\
\hline $\begin{array}{l}\text { From } \\
\text { urological } \\
\text { assessment } \\
\text { to } \\
\text { procedure } \\
\text { (days) }\end{array}$ & 15 & $14.2(30.8)$ & $3(1-120)$ & 28 & $10.9(14.6)$ & $\begin{array}{c}6.0 \\
(1-64)\end{array}$ & 0.6347 \\
\hline
\end{tabular}

ED: emergency department; IQR: interquartile range; SD: standard deviation. 
Table 6. Results of emergency physician survey $(\mathrm{n}=20)$

\begin{tabular}{|r|c|}
\hline Statements regarding physician satisfaction & Mean score \\
\hline Patient flow and system improvement & \\
1. Since the introduction of the Acute Care urology clinic, I feel more & 4.84 \\
confident patients will be seen by urology in a timely manner as an & \\
$\quad$ outpatient & 4.84 \\
2. I feel follow up is easy to arrange and accessible & 3.95 \\
3. I am able to discharge patients sooner from ED (decrease length of & 4.58 \\
stay) & 4.84 \\
4. I am less likely to page urology on call & 3.90 \\
5. I feel the clinic has made a positive impact on patient care & 4.60 \\
6. I predict there has been a decrease in patient return or repeat visits & \\
for urological complaints (i.e., renal colic, hematuria, catheter & \\
problems) & \\
\hline
\end{tabular}

Scoring system: 1 - strongly disagree; 2 - disagree; 3 - neutral; 4 - agree; 5 - strongly agree; ED: emergency department.

\begin{tabular}{|c|c|}
\hline Statements regarding surgeon satisfaction & Mean score \\
\hline $\begin{array}{l}\text { 1. I believe that after-hours surgeries contribute to surgeon burnout } \\
\text { and dissatisfaction (after-hours surgeries are defined as surgeries } \\
\text { scheduled in the evenings and weekends). }\end{array}$ & 4.5 \\
\hline $\begin{array}{l}\text { 2. I believe that since ACU implementation, patient consults are } \\
\text { performed in a more timely fashion. }\end{array}$ & 5 \\
\hline $\begin{array}{l}\text { 3. I believe that since ACU implementation, patient consults are } \\
\text { performed in a more timely fashion. }\end{array}$ & 5 \\
\hline $\begin{array}{l}\text { 4. I believe that acute urology patients are operated on in a more } \\
\text { timely fashion since implementation of ACU. }\end{array}$ & 5 \\
\hline $\begin{array}{l}\text { 5. I believe that acute urology patient outcomes have improved since } \\
\text { implementation of ACU. }\end{array}$ & 5 \\
\hline $\begin{array}{l}\text { 6. I prefer to perform acute care urology surgeries during the daytime } \\
\text { (in comparison to after-hours). }\end{array}$ & 5 \\
\hline
\end{tabular}

Scoring system: 1 - strongly disagree; 2 - disagree; 3 - neutral; 4 - agree; 5 - strongly agree. ACU: acute care urology. 
Table 8. Results of patient feedback survey $(n=11)$

Responses at the urology clinic from July 4, 2017 to September 6, 2017

\begin{tabular}{|c|l|c|c|c|c|}
\hline \multicolumn{2}{|l|}{} & Always & Sometimes & Never & N/A \\
\hline 1 & $\begin{array}{l}\text { The staff at the front } \\
\text { desk were polite and } \\
\text { courteous }\end{array}$ & $\begin{array}{c}100 \% \\
(11 / 11)\end{array}$ & $\begin{array}{c}0 \% \\
(0 / 11)\end{array}$ & $\begin{array}{c}0 \% \\
(0 / 11)\end{array}$ & $\begin{array}{c}0 \% \\
(0 / 11)\end{array}$ \\
\hline 2 & $\begin{array}{l}\text { I felt my privacy was } \\
\text { respected }\end{array}$ & $\begin{array}{c}100 \% \\
(11 / 11)\end{array}$ & $\begin{array}{c}0 \% \\
(0 / 11)\end{array}$ & $\begin{array}{c}0 \% \\
(0 / 11)\end{array}$ & $\begin{array}{c}0 \% \\
(0 / 11)\end{array}$ \\
\hline 3 & $\begin{array}{l}\text { Tests, test results and } \\
\text { procedures were } \\
\text { explained to me clearly } \\
\text { so I could understand }\end{array}$ & $\begin{array}{c}90.9 \% \\
(10 / 11)\end{array}$ & $\begin{array}{c}0 \% \\
(0 / 11)\end{array}$ & $\begin{array}{c}0 \% \\
(0 / 11)\end{array}$ & $\begin{array}{c}9.1 \% \\
(1 / 11)\end{array}$ \\
\hline 4 & $\begin{array}{l}\text { I was told what } \\
\text { symptoms to watch for } \\
\text { after I left the clinic }\end{array}$ & $\begin{array}{c}100 \% \\
(11 / 11)\end{array}$ & $\begin{array}{c}0 \% \\
(0 / 11)\end{array}$ & $\begin{array}{c}0 \% \\
(0 / 11)\end{array}$ & $\begin{array}{c}0 \% \\
(0 / 11)\end{array}$ \\
\hline 5 & $\begin{array}{l}\text { I was told what } \\
\text { symptoms to watch for } \\
\text { after I left the clinic }\end{array}$ & $\begin{array}{l}81.8 \% \\
(9 / 11)\end{array}$ & $\begin{array}{c}9.1 \% \\
(1 / 11)\end{array}$ & $\begin{array}{c}0 \% \\
(0 / 11)\end{array}$ & $\begin{array}{c}9.1 \% \\
(1 / 11)\end{array}$ \\
\hline 6 & $\begin{array}{l}\text { My scheduled } \\
\text { test/procedures were } \\
\text { done in a timely manner }\end{array}$ & $\begin{array}{c}90.9 \% \\
70 / 11)\end{array}$ & $\begin{array}{c}9.1 \% \\
(1 / 11)\end{array}$ & $\begin{array}{c}0 \% \\
(0 / 11)\end{array}$ & $\begin{array}{c}0 \% \\
(0 / 11)\end{array}$ \\
\hline 7 & $\begin{array}{l}\text { My wait time from the } \\
\text { time I was seen in the } \\
\text { emergency room to my } \\
\text { appointment to see the } \\
\text { urologist in the Baruch } \\
\text { Weisz Clinic was timely }\end{array}$ & $\begin{array}{c}100 \% \\
(11 / 11)\end{array}$ & $\begin{array}{c}0 \% \\
(0 / 11)\end{array}$ & $\begin{array}{c}0 \% \\
(0 / 11)\end{array}$ & $\begin{array}{c}0 \% \\
(0 / 11)\end{array}$ \\
\hline 8 & $\begin{array}{l}\text { I was given information } \\
\text { about what would } \\
\text { happen next regarding } \\
\text { my care }\end{array}$ & $\begin{array}{c}100 \% \\
(11 / 11)\end{array}$ & $\begin{array}{c}0 \% \\
(0 / 11)\end{array}$ & $\begin{array}{c}0 \% \\
(0 / 11)\end{array}$ & $\begin{array}{c}0 \% \\
(0 / 11)\end{array}$ \\
\hline 9 & $\begin{array}{l}\text { I had an overall good } \\
\text { experience }\end{array}$ & $\begin{array}{c}100 \% \\
(11 / 11)\end{array}$ & $(0 / 11)$ & $0 \%$ \\
\hline
\end{tabular}

